\title{
Green Synthesis: Novel method for Substituted Anilines from its Benzyl Azides
}

\author{
Gondi Sudershan Reddy ${ }^{*}$
}

\author{
Affiliations: \\ ${ }^{1}$ Departments of Chemistry, National Taiwan Normal University, Taipei, Taiwan 116 (ROC). \\ a Correspondence to: gondisr@gmail.com.
}

Abstract: A unique and novel synthetic method was developed to generate substituted anilines from its benzyl azides having ortho/para electron withdrawing group (EWG), and when these groups are at meta position gives aldehyde, instead. This approach is an inexpensive, simple, fast, efficient at room temperature. This protocol is easily amenable to large scale preparation.

Key Words: substituted benzylazides, green chemistry, selectivity, electron withdrawing groups, substituted anilines and extrusion of carbon.

Introduction: In recent years organic azides received considerable attention as potential precursors of primary amines, amides, imines, versatile synthetic intermediate for nitrogen containing heterocyclic compounds, pharmaceutical drugs ${ }^{1,2,3}$ and agricultural chemistry. ${ }^{4,-7}$ Due to its attractive applications in organic synthesis, a number of methods for the preparation of azides (whether aliphatic or aromatic azides) with excellent regio and stereo control were developed. Conversion of azide to primary amines is an important process. There are many reports on this conversion for example; LAH $^{8}$, triethyl phosphate ${ }^{9,10}$, TPP ${ }^{11}$, sodium hydrogen telluride ${ }^{12}$, borohydride ${ }^{13}$, ${\text { Bakers' }{ }^{\prime} \text { east }}^{14}$, lodotrimethylsilane ${ }^{15}$, tributyltinhydride ${ }^{16}$, indium ${ }^{17}$, catalytic hydrogenation ${ }^{18,19}$, Samarium ${ }^{20}, \mathrm{Zn} / \mathrm{NH}_{4} \mathrm{Cl}^{21}$, Borane-DMS ${ }^{22}, \mathrm{TBN}^{23}$ and Grignard reagent ${ }^{24}$ have been reported. All these synthetic methods go with retaining of 
methylene carbon adjacent to azide. There are two methods are reported, were rearranging of benzylazides carbon as part of products ${ }^{25,26}$. However, so far there is no efficient and straightforward methods were reported for the modification of substituted benzyl azide to substituted aniline by the extrusion of carbon. On the other hand, the organic solvents free chemical transformations are important co-friendly tool for promoting "green chemistry" strategy, developing any methods by using green chemistry protocols are particularly useful from environmental aspects.

Present work: During our own efforts in green chemistry, we obtained substituted anilines from its corresponding benzylic azides having ortho or para electron withdrawing groups (EWD). When these substrates are at meta position gives substituted benzaldehyde.

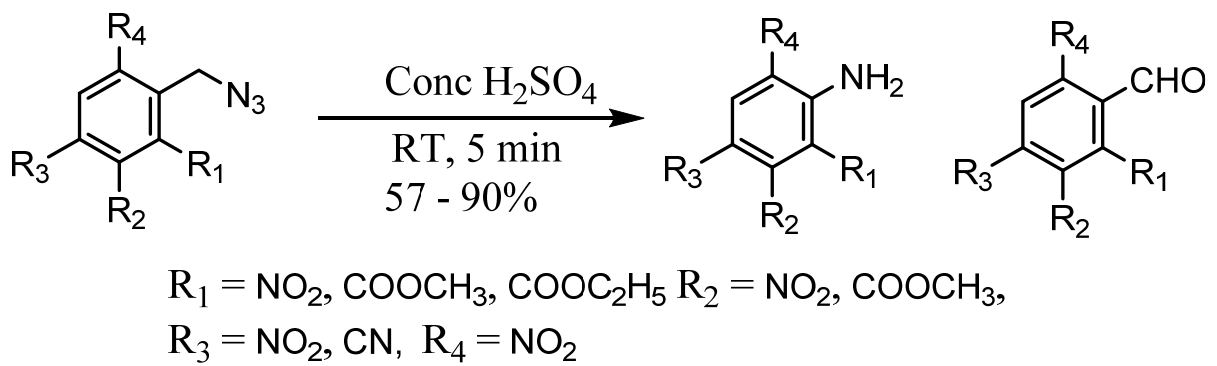

To establish the optimum conditions, we first examined the reaction of $\mathbf{1}$ with various percentages of sulfuric acid at different temperatures, (no reaction occurs in diluted sulfuric acid or hydrochloric acid). The best results were obtained in the presence of $98 \%$ concentrated sulfuric acid at room temperature for 5 minutes. The results are summarized in the table 1 .

Table-1, Conversion of Benzylic Azide to Amine<smiles>CCOC(=O)c1cccc([N+](=O)[O-])c1N</smiles> 


\begin{tabular}{|c|c|c|c|c|}
\hline Entry & Acid & Temp & Time & Yield(\%) \\
\hline 1 & ${\text { Conc } \mathrm{H}_{2} \mathrm{SO}_{4}}$ & $\mathrm{RT}$ & $5 \mathrm{~min}$ & 89 \\
2 & $80 \% \mathrm{H}_{2} \mathrm{SO}_{4}$ & $\mathrm{RT}$ & $18 \mathrm{~h}$ & $\mathrm{NR}$ \\
3 & $50 \% \mathrm{H}_{2} \mathrm{SO}_{4}$ & $\mathrm{RT}$ & $18 \mathrm{~h}$ & $\mathrm{NR}$ \\
4 & $\mathrm{Conc} \mathrm{HCl}$ & $\mathrm{RT}$ & $24 \mathrm{~h}$ & $\mathrm{NR}$ \\
\hline
\end{tabular}

The scope of this general procedure is shown in table 2. Substrate with two electron withdrawing groups (nitro and ester) at ortho position (entry 1,2,3, in table 2) and with one electron withdrawing group (nitro or ester) at ortho or para position (entry 4-7, in table 2) gives expected products in $75-89 \%$ yield. Presence of EWD nitro group (strong) and sulfonamide (weak) at meta position in combination of strong electron drawing group (ester) at ortho position shows no effect on the outcome of the results. (entry $8,9,10)$. Same substrate (entry 9,10$)$ when heated at $100^{\circ} \mathrm{C}$ gives diamines after desulfonation in $63-65 \%$ respectively.

Table-2

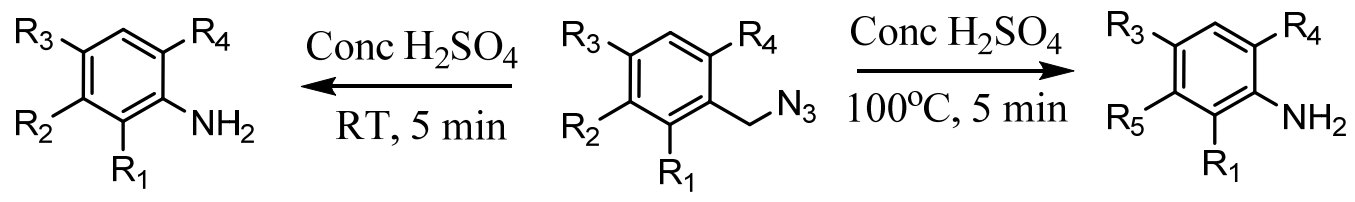

\begin{tabular}{|c|c|c|c|c|c|c|c|c|}
\hline Entry & Substrate & $\mathbf{R}_{1}$ & $\mathbf{R}_{\mathbf{2}}$ & $\mathbf{R}_{\mathbf{3}}$ & $\mathbf{R}_{\mathbf{4}}$ & $\mathbf{R}_{\mathbf{5}}$ & RT Yield (\%) & $100^{\circ} \mathrm{C}$ Yield (\%) \\
\hline 1 & $1 \mathrm{a}$ & $\mathrm{NO}_{2}$ & $\mathrm{H}$ & $\mathrm{H}$ & $\mathrm{CO}_{2} \mathrm{CH}_{2} \mathrm{CH}_{3}$ & N/A & $2 a, 89$ & $N / A$ \\
\hline 2 & $1 \mathrm{~b}$ & $\mathrm{NO}_{2}$ & $\mathrm{H}$ & $\mathrm{H}$ & $\mathrm{CO}_{2} \mathrm{CH}_{3}$ & $\mathrm{~N} / \mathrm{A}$ & $2 b, 85$ & $N / A$ \\
\hline 3 & $1 \mathrm{c}$ & $\mathrm{NO}_{2}$ & $\mathrm{H}$ & $\mathrm{H}$ & $\mathrm{NO}_{2}$ & $\mathrm{~N} / \mathrm{A}$ & $2 c, 80$ & N/A \\
\hline 4 & $1 d$ & $\mathrm{CO}_{2} \mathrm{CH}_{3}$ & $\mathrm{H}$ & $\mathrm{H}$ & $\mathrm{H}$ & $\mathrm{N} / \mathrm{A}$ & $2 d, 83$ & $\mathrm{~N} / \mathrm{A}$ \\
\hline 5 & $1 e$ & $\mathrm{NO}_{2}$ & $\mathrm{H}$ & $\mathrm{H}$ & $\mathrm{H}$ & $\mathrm{N} / \mathrm{A}$ & $2 e, 75$ & N/A \\
\hline 6 & $1 f$ & $\mathrm{H}^{2}$ & $\mathrm{H}$ & $\mathrm{NO}_{2}$ & $\mathrm{H}$ & $\mathrm{N} / \mathrm{A}$ & $2 f, 79$ & $N / A$ \\
\hline 7 & $1 \mathrm{~g}$ & $\mathrm{H}$ & $\mathrm{H}$ & $\mathrm{CN}$ & $\mathrm{H}$ & N/A & $2 \mathrm{~g}, 77$ & N/A \\
\hline 8 & $1 \mathrm{~h}$ & $\mathrm{CO}_{2} \mathrm{CH}_{3}$ & $\mathrm{NO}_{2}$ & $\mathrm{H}$ & $\mathrm{H}$ & N/A & $2 \mathrm{~h}, 78$ & $N / A$ \\
\hline 9 & $1 \mathrm{i}$ & $\mathrm{CO}_{2} \mathrm{CH}_{3}$ & $\mathrm{~N}(\mathrm{H}) \mathrm{SO}_{2} \mathrm{Ph}-4 \mathrm{NO}_{2}$ & $\mathrm{H}$ & $\mathrm{H}$ & $\mathrm{NH}_{2}$ & $2 \mathrm{i}, 90$ & $3 i, 60$ \\
\hline 10 & $1 \mathrm{j}$ & $\mathrm{CO}_{2} \mathrm{CH}_{3}$ & $\mathrm{~N}\left(\mathrm{CH}_{3}\right) \mathrm{SO}_{2} \mathrm{Ph}-4 \mathrm{NO}_{2}$ & $\mathrm{H}$ & $\mathrm{H}$ & $\mathrm{NHCH}_{3}$ & 2j, 87 & $3 \mathrm{j}, 65$ \\
\hline
\end{tabular}

Table 3: When nitro group at para position and ester group at meta position give mixture of products, amine (major) along with aldehyde (minor) product were isolated (entry 1 in table 3 ). We found, the electron withdrawing group (ester) at meta position is 
favored for aldehyde formation. To further confirm, we treated a substituent with ester group at meta position and sulfonamide (weak EWG) group at para position under similar reaction condition, it gives exclusively aldehyde-sulfonamide (not isolated, check by LCMS), which on further heating $100^{\circ} \mathrm{C}$ gives the desulphonated aldehyde-amine ${ }^{27}$ table-3, entry 2) where Suzuki coupling and ozonolysis used in reported method for this compound. The formation of $3 \mathrm{~m}$ (entry 3 , table 3 ) from $1 \mathrm{~m}$ further confirm, that ester group at meta position gives aldehyde. Even though conversion of benzylazides to aldehyde were well documented in literature ${ }^{28,29}$, the present method is selectively give aldehyde from substituted benzyl azides having meta EWD group. This process is useful for separation of meta isomer having EWD group from its ortho-para isomers.

Table-3

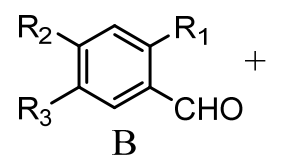<smiles>[R]c1cc([R])c(N)c(N)c1</smiles><smiles></smiles><smiles>[R]c1cc([R])c(CN)cc1[R]</smiles>

\begin{tabular}{|c|c|c|c|c|c|c|c|c|}
\hline Entry & Substrate & $\mathbf{R}_{1}$ & $\mathbf{R}_{\mathbf{2}}$ & $\mathbf{R}_{3}$ & $\mathbf{R}_{\mathbf{4}}$ & RT Yield A (\%) & RT Yield B (\%) & $100^{\circ} \mathrm{C}$ Yield (\%) \\
\hline 1 & $1 \mathrm{k}$ & $\mathrm{NO}_{2}$ & $\mathrm{H}$ & $\mathrm{CO}_{2} \mathrm{CH}_{3}$ & $\mathrm{~N} / \mathrm{A}$ & $2 \mathrm{k}, 58$ & $3 \mathrm{k}, 18$ & N/A \\
\hline 1 & 11 & $\mathrm{H}$ & $\mathrm{N}\left(\mathrm{CH}_{3}\right) \mathrm{SO}_{2} \mathrm{Ph}-4 \mathrm{CH}_{2} \mathrm{~N}_{3}$ & $\mathrm{CO}_{2} \mathrm{CH}_{3}$ & $\mathrm{NHCH}_{3}$ & $N / A$ & $N / A$ & 31,74 \\
\hline 1 & $1 \mathrm{~m}$ & $\mathrm{H}$ & $\mathrm{H}$ & $\mathrm{CO}_{2} \mathrm{CH}_{3}$ & $N / A$ & NA & $3 m, 78$ & \\
\hline
\end{tabular}

General procedure: To a $0.2-1.2 \mathrm{mmol}$ of azide compound in 1-2 $\mathrm{mL}$ of conc. sulfuric acid and stirred at room temperature (or $100^{\circ} \mathrm{C}$ ) for 5 minutes. Reaction was monitored by TLC/GC. After the completion of reaction, the reaction mixture was diluted with water and extracted with ethyl acetate. The combined organic layer was washed with water, brine, dried over anhydrous $\mathrm{MgSO}_{4}$ and filtered. The solvent was removed under vacuum and the crude product purified by flash column chromatography to give pure product in $60-90 \%$ yield. 


\section{Proposed mechanism:}

Figure-1, plausible mechanism with Ortho Ester group

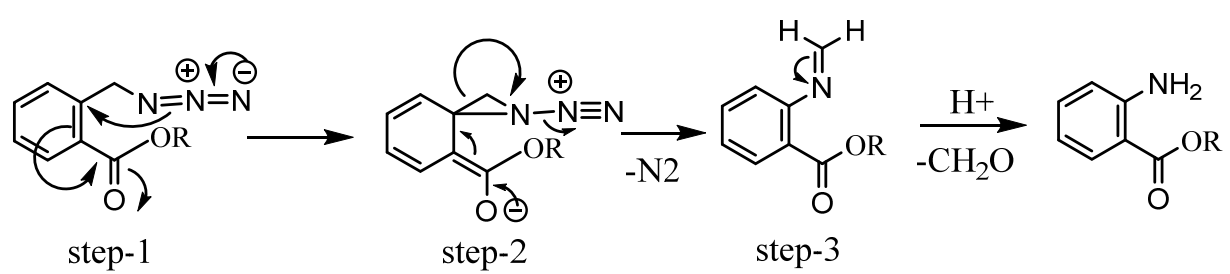

The conversion of benzyl azide to aromatic amines (chopping, one carbon loss) is new to literature. The mechanism is similar to as explained for the preparation of nicotine ${ }^{3}$, it is plausible that electron ${ }^{30}$ withdrawing groups is playing a significant (stabilize the intermediate) role during amines formation via aziridine ring intermediate, which subsequently open to liberate nitrogen $(\mathrm{g})$ and formed imines, which on hydrolyzed in acidic medium to give the substituted anilines.

conclusion, we have found a novel method for the synthesis of a variety of substituted amines from its benzylic azides having ortho or para positioned electron withdrawing group under acid medium. Functional groups such as cyano, nitro, ester, and sulfonamides are survived in this condition. The results illustrate the potential utility of this method as an environment-friendly process to converts non-functional methyl group (alpha to EWD group) to functional group, amine. Diamines, particularly unsymmetrical were synthesized by these method were useful in coupling with cysteine specific modifiers to investigate cytochrome-c folding kinetics in protein modification ${ }^{31}$.

\section{- Corresponding Author Information}

Corresponding Author: Gondi Sudershan Reddy, email: gondisr@gmail.com

\section{- Acknowledgement}

G.S.R thankful to National Science Council of Taiwan, (ROC) for financial support in the form of Post-Doctoral Fellowship during February 2000-July 2003. G.S.R is thankful to 
Chang I jy and Kwunmin Chen at National Taiwan Normal University, Taipei, Taiwan, for conducting the experiments and collection and processing of the spectral data and X-ray data are gratefully acknowledged.

- Competing interests: There is no Competing Interests pending

- Data and materials availability: Crystallographic model data is available through the CCDC under identifier 1976539 (Ethyl-2-amino-3-nitro-benzoate, 2a, CAS 61063-11-4), 1976533 (Methyl-2-amino-6-nitro-benzoate, 2h, CAS 57113-89-0), 2004669 (2-Methyl6-[methyl-(4-nitro-benzenesulfonyl)-amino]-benzoic acid methyl ester, 19) and 2004667 (2-Bromomethyl-6-[methyl-(4-nitro-benzenesulfonyl)-amino]-benzoic acid methyl ester, 20),

\section{Reference:}

1 Compton, D. R. et al. Synthesis and pharmacological evaluation of amino, azido, and nitrogen mustard analogs of 10-substituted cannabidiol and 11- or 12-substituted .DELTA.8-tetrahydrocannabinol. Journal of Medicinal Chemistry 33, 1437-1443, doi:10.1021/jm00167a025 (1990).

2 Perumattam, J., Shearer, B. G., Confer, W. L. \& Mathew, R. M. Synthesis of (D)- and (L)-forms of differentially protected 2-piperidinemethanamine. Tetrahedron Letters 32 , 7183-7186, doi:https://doi.org/10.1016/0040-4039(91)80471-H (1991).

3 Nyfeler, E. \& Renaud, P. Intramolecular Schmidt reaction: applications in natural product synthesis. Chimia 60, 276-284, doi:10.2533/000942906777674714 (2006).

4 Smith, S. C. \& Heathcock, C. H. A convenient procedure for the synthesis of bis-steroidal pyrazines: models for the cephalostatins. The Journal of Organic Chemistry 57, 63796380, doi:10.1021/jo00050a002 (1992).

5 McDonald, F. E. \& Danishefsky, S. J. A stereoselective route from glycals to asparaginelinked N-protected glycopeptides. The Journal of Organic Chemistry 57, 7001-7002, doi:10.1021/jo00052a001 (1992).

6 Scriven, E. F. V. \& Turnbull, K. Azides: their preparation and synthetic uses. Chemical Reviews 88, 297-368, doi:10.1021/cr00084a001 (1988).

7 Tomioka, H., Ichikawa, N. \& Komatsu, K. Photochemistry of 2(methoxycarbonyl)phenyl azide studied by matrix-isolation spectroscopy. A new slippery energy surface for phenylnitrene. Journal of the American Chemical Society 115, 86218626, doi:10.1021/ja00072a015 (1993).

8 Boyer, J. H. Reduction of Organic Azides to Primary Amines with Lithium Aluminum Hydride. Journal of the American Chemical Society 73, 5865-5866, doi:10.1021/ja01156a507 (1951). 
9 Meguro, T., Yoshida, S. \& Hosoya, T. Aromatic Azido-selective Reduction via the Staudinger Reaction Using Tri-n-butylphosphonium Tetrafluoroborate with Triethylamine. Chemistry Letters 46, 473-476, doi:10.1246/cl.161159 (2017).

10 Yoshida, S., Misawa, Y. \& Hosoya, T. Formal C-H-Azidation Based Shortcut to Diazido Building Blocks for the Versatile Preparation of Photoaffinity Labeling Probes. Eur. $J$. Org. Chem. 2014, 3991-3995, doi:10.1002/ejoc.201402516 (2014).

11 Lee, J. W. \& Fuchs, P. L. Reduction of Azides to Primary Amines in Substrates Bearing Labile Ester Functionality. Synthesis of a PEG-Solubilized, "Y"-Shaped Iminodiacetic Acid Reagent for Preparation of Folate-Tethered Drugs1. Organic Letters 1, 179-182, doi:10.1021/o19905248 (1999).

12 Vaultier, M., Knouzi, N. \& Carrié, R. Reduction d'azides en amines primaires par une methode generale utilisant la reaction de staudinger. Tetrahedron Letters 24, 763-764, doi:https://doi.org/10.1016/S0040-4039(00)81520-8 (1983).

13 Kilbas, B., Yilmaz, Y. E. \& Ergen, S. A practical and highly efficient transfer hydrogenation of aryl azides using a [Ru(p-cymene)Cl2]2 catalyst and sodium borohydride. Comptes Rendus Chimie 21, 880-883, doi:https://doi.org/10.1016/j.crci.2018.07.004 (2018).

14 Baruah, M., Boruah, A., Prajapati, D. \& Sandhu, J. S. Bakers’ Yeast Mediated Chemoselective Reduction of Azidoarenes. Synlett 1996, 1193-1194, doi:10.1055/s1996-5710 (1996).

15 Kamal, A., Rao, N. V. \& Laxman, E. Iodotrimethylsilane: a mild and efficient reagent for the reduction of azides to amines. Tetrahedron Lett. 38, 6945-6948, doi:10.1016/S00404039(97)01628-6 (1997).

16 Bartra, M., Romea, P., Urpí, F. \& Vilarrasa, J. A fast procedure for the reduction of azides and nitro compounds based on the reducing ability of $\mathrm{Sn}(\mathrm{SR}) 3$-species.

Tetrahedron 46, 587-594, doi:https://doi.org/10.1016/S0040-4020(01)85439-9 (1990).

17 Gerner Seitzberg, J., Titilola Akinleminu Kronborg, T., Poljak, V., Friberg, G. \& Teuber, L. Heterocyclic compounds as bromodomain Inhibitors and their preparation. WO2016016316A1 (2016).

18 Shin, Y. G. et al. Method for preparation of aminobenzylamine. KR2013077451A (2013).

19 Koshi, Y. et al. Target-Specific Chemical Acylation of Lectins by Ligand-Tethered DMAP Catalysts. Journal of the American Chemical Society 130, 245-251, doi:10.1021/ja075684q (2008).

20 Huang, Y., Zhang, Y. \& Wang, Y. Facile reduction of azides to the corresponding amines with metallic samarium and catalytic amount of lodine. Tetrahedron Letters 38, 10651066, doi:https://doi.org/10.1016/S0040-4039(96)02480-X (1997).

21 Lin, W. et al. REDUCTION OF AZIDES TO AMINES OR AMIDES WITH ZINC AND AMMONIUM CHLORIDE AS REDUCING AGENT. Synthetic Communications 32, 3279-3284, doi:10.1081/SCC-120014032 (2002).

22 Salunkhe, A. M., Veeraraghavan Ramachandran, P. \& Brown, H. C. Selective reductions. Part 60: Chemoselective reduction of organyl azides with dichloroborane-dimethyl sulfide. Tetrahedron 58, 10059-10064, doi:https://doi.org/10.1016/S0040$\underline{4020(02) 01322-4}(2002)$. 
23 Barral, K., Moorhouse, A. D. \& Moses, J. E. Efficient Conversion of Aromatic Amines into Azides: A One-Pot Synthesis of Triazole Linkages. Organic Letters 9, 1809-1811, doi:10.1021/o1070527h (2007).

24 Gao, H. et al. Rapid heteroatom transfer to arylmetals utilizing multifunctional reagent scaffolds. Nat. Chem. 9, 681-688, doi:10.1038/nchem.2672 (2017).

25 Wendlandt, A. E. \& Stahl, S. S. Modular o-Quinone Catalyst System for Dehydrogenation of Tetrahydroquinolines under Ambient Conditions. J. Am. Chem. Soc. 136, 11910-11913, doi:10.1021/ja506546w (2014).

26 Che, Y., Wang, R., Fu, Y. \& Du, Z. Acid-Mediated Denitrogenation/Rearrangement/Coupling of Benzyl Azides with Triazolyl-Substituted Cycloalkanones. Synlett 31, 388-392, doi:10.1055/s-0037-1610747 (2020).

27 Beaulieu, P. L. et al. Preparation of 2-amido benzoic acid compounds as viral polymerase inhibitors. WO2009076747A1 (2009).

28 Giovani, S., Singh, R. \& Fasan, R. Efficient conversion of primary azides to aldehydes catalyzed by active site variants of myoglobin. Chemical Science 7, 234-239, doi:10.1039/C5SC02857D (2016).

29 Barragan, E. \& Bugarin, A. $\pi$-Conjugated Triazenes: Intermediates That Undergo Oxidation and Substitution Reactions. The Journal of Organic Chemistry 82, 1499-1506, doi:10.1021/acs.joc.6b02705 (2017).

30 Dyall, L. K. \& Karpa, G. J. Pyrolysis of Aryl Azides. VIII. Hammett Correlations of Rates of Pyrolysis of Substituted 2-Azidobenzophenones. Australian Journal of Chemistry 41, 1231-1241 (1988).

31 Reddy, G. S., Chen, H.-Y. \& Chang, I. J. Cysteine-Specific Blue Fluorescence Probe. Journal of the Chinese Chemical Society 53, 1303-1308, doi:10.1002/jccs.200600174 (2006). 